\title{
Factors affecting motorcycle helmet use in the population of Greater Athens, Greece
}

\begin{abstract}
Alkistis Skalkidou, Eleni Petridou, Fotios C Papadopoulos, Nick Dessypris, Dimitrios Trichopoulos
\end{abstract}

\begin{abstract}
Objectives-Helmet use is the best preventive measure available against two wheel motorized vehicle (TWMV) related head injuries. In some countries, however, helmets are used only by a minority of TWMV riders. In collaboration with the Road Traffic Police Department, an inspection survey was undertaken to assess the prevalence and to determine predictors of helmet use.
\end{abstract}

Setting-The Greater Athens area, Greece, during July and August 1998. Methods-A total of 982 TWMVs were stopped, 349 of which had two riders $(36 \%)$. All riders were interviewed by staff members of the Centre for Research and Prevention of Injuries among the Young.

Results-The average prevalence of helmet use was $20.2 \%$. It ranged from $9.7 \%$ on small suburban roads to $50.8 \%$ on highways. Prevalence of use was significantly lower during the weekend days and at night. Women were significantly more likely to wear a helmet and, controlling for gender, drivers were significantly more likely to be helmet users. Riders of more powerful TWMVs and passengers, who themselves had a TWMV driving license, were helmet users more frequently. Among non-users, the majority (46\%) indicated that "the helmet made them feel uncomfortable", particularly in warm weather, whereas $18 \%$ claimed that there was little need for a helmet in low speed riding.

Conclusions-A multipronged campaign is urgently needed in Greece to increase the prevalence of helmet use by TWMV riders. The campaign should include not only police enforcement but also initiatives to make helmets more convenient to wear and less expensive.

(Injury Prevention 1999;5:264-267)

Keywords: motorcycle helmet; motorcyclist; risk factor; road traffic accident

Mortality from road traffic injuries in Greece follows an upward trend, whereas in several European countries it has dramatically decreased. ${ }^{1}$ For example, Greece has had an average increase in annual two wheel motorized vehicle (TWMV) rider deaths of $8.8 \%$ per year from 1980 to 1993; in the United Kingdom and in Sweden, however, the corresponding percentages were $-4.5 \%$ per year and $-1.9 \%$ per year. Greece ranks second worst among other European countries with an annual road traffic injuries toll exceeding 2500 deaths per year.

The proportion of injuries caused during collisions that include TWMVs is very high, and also shows an upward trend, following the increasing number of licensed TWMVs. TWMVs include motorbikes, which possess engines of $50 \mathrm{cc}$ or less, and motorcycles, which possess more powerful engines. Two wheel vehicles represent an inexpensive and easy to use means of transportation, ${ }^{2}$ both in the heavy traffic of large cities, notably Athens, and also in the isolated parts of Greek islands. The number of private TWMVs in 1997 was twice that of the corresponding number 10 years ago, while the number of private cars has increased by only $60 \%$ over the same period.

The majority of TWMV riders involved in road accidents are young people, who generally tend to adopt risky attitudes and behaviors. ${ }^{3-5}$ Many young TWMV users in Greece frequently ride without a helmet, even though helmet use has been mandatory both for TWMV drivers and passengers since 1977, possibly because of the inadequate enforcement of the law. The difficulty in enforcing a law which is massively resisted is widely known, but substituting "wearing" in place of the word "carrying", should help the implementation of this law. Helmet use laws are well established as factors contributing to the high helmet wearing rates in many countries where the law is strictly enforced. ${ }^{6-11}$

No routine data for helmet use are available in Greece: according to traffic police injury data and everyday experience, the estimated prevalence of helmet use is extremely low, especially during the warm months of the year. Traffic police data indicate that among those who were killed in fatal crashes, the frequency of helmet use was $11 \%$, whereas among those injured, the frequency of helmet use was higher, at $16 \%$.

Helmet use has been shown to be highly effective in reducing the adverse outcomes of TWMV injuries ${ }^{12-17}$ and contributing to the reduction of health care expenses. ${ }^{18-23}$ From a nationwide study in Greece, it was estimated that if all TWMV riders were using safety helmets, some 200 deaths per year could have been avoided. ${ }^{24}$

This study attempts to estimate helmet use patterns in the Greater Athens area, and to determine factors affecting use of helmets, in order to propose evidence based means to address this important public health problem. The population of the Greater Athens area 
Table 1 Distribution of the 1331 interviewed TWMV riders by the use of helmet and studied variables; values are number (\%)

\begin{tabular}{|c|c|c|c|}
\hline \multirow[b]{2}{*}{ Variable } & \multicolumn{2}{|l|}{ Use of helmet } & \multirow[b]{2}{*}{$p$ Value } \\
\hline & Yes & No & \\
\hline Place of inspection & & & $0.001^{\star}$ \\
\hline Suburban roads & $57(9.7)$ & $528(90.3)$ & \\
\hline Main roads & $79(16.3)$ & $405(83.7)$ & \\
\hline Highways & $133(50.8)$ & $129(49.2)$ & \\
\hline Day of inspection & & & $0.082 \dagger$ \\
\hline Weekday & $211(21.3)$ & $778(78.7)$ & \\
\hline Weekend & $58(17.0)$ & $284(83.0)$ & \\
\hline Time of inspection & & & $0.001 \dagger$ \\
\hline Day & $214(23.5)$ & 697 (76.5) & \\
\hline Night & $55(13.1)$ & $365(86.9)$ & \\
\hline Gender and position of TWMV rider & & & $0.001^{\star}$ \\
\hline Male driver & $220(23.8)$ & 705 (76.2) & \\
\hline Male passenger & $7(6.4)$ & $102(93.6)$ & \\
\hline Female driver & $14(24.6)$ & $43(75.4)$ & \\
\hline Female passenger & $28(11.7)$ & $212(88.3)$ & \\
\hline Age (years) & & & $0.001 \ddagger$ \\
\hline$\leqslant 24$ & $55(23.6)$ & $408(176.4)$ & \\
\hline $25-34$ & $130(24.1)$ & $409(75.9)$ & \\
\hline $35-44$ & $55(25.4)$ & $162(74.6)$ & \\
\hline $45+$ & $29(26.0)$ & $83(74.0)$ & \\
\hline TWMV power capacity (cc) & & & $0.001 \ddagger$ \\
\hline$\leqslant 50$ & $62(14.3)$ & $370(85.7)$ & \\
\hline $51-200$ & $53(12.6)$ & $366(87.4)$ & \\
\hline $201-400$ & $90(31.8)$ & $193(68.2)$ & \\
\hline $401+$ & $64(32.5)$ & $133(67.5)$ & \\
\hline Age of the TWMV (years) & & & $0.12 \ddagger$ \\
\hline $0-1$ & $95(17.9)$ & $439(82.1)$ & \\
\hline $2-5$ & $93(21.6)$ & $337(78.4)$ & \\
\hline $6-9$ & $43(20.9)$ & $163(79.1)$ & \\
\hline $10+$ & $38(23.2)$ & $126(76.8)$ & \\
\hline Consider helmet useful in reducing risk & & & $0.003 \dagger$ \\
\hline Yes & $235(21.8)$ & $843(78.2)$ & \\
\hline No & $34(13.4)$ & $219(86.6)$ & \\
\hline Issue year of the driving licence & & & $0.001^{\star}$ \\
\hline no driving licence & $32(9.7)$ & $299(90.3)$ & \\
\hline$<1990$ & $119(27.2)$ & $319(72.8)$ & \\
\hline 1990-1995 & $66(22.8)$ & $224(77.2)$ & \\
\hline $1996+$ & $52(19.1)$ & $220(80.9)$ & \\
\hline
\end{tabular}

${ }^{\star} \mathrm{p}$ Value derived from $\chi^{2}$ test with (n-1) degree of freedom; tp value derived from $\chi^{2}$ test with 1 degree of freedom; $\neq p$ value derived from trend test.

according to the census of 1991 is approximately four million-that is, $40 \%$ of the total Greek population.

\section{Methods}

An inspection survey of helmet use was conducted in July and August 1998. July and August are usually the hottest months in Greece. Teams consisting of one of three trained interviewers, staff members of the Centre for Research and Prevention of Injuries among the Young (CEREPRI) and one road traffic policeman, randomly stopped TWMVs in 10 sites of randomly selected secondary

Table 2 Multiple logistic regression derived odds ratio (OR) and 95\% confidence interval ( $95 \%$ CI) for the use of the helmet, associated with a series of potential risk factors

\begin{tabular}{lllll}
\hline Variables & Category or unit & OR & 95\% CI & p Value \\
\hline Place of inspection & Suburban roads & 0.67 & 0.45 to 0.97 & 0.04 \\
& Main road & 1.00 & & \\
& Highways & 6.25 & 4.35 to 9.09 & 0.0001 \\
Day of inspection & Weekday & 1.00 & & \\
& Weekend & 0.65 & 0.43 to 0.95 & 0.03 \\
Time of inspection & Day & 1.00 & & \\
& Night & 0.68 & 0.48 to 0.98 & 0.04 \\
Gender and position of the TWMV rider & Male driver & 1.00 & & \\
& Male passenger & 0.36 & 0.14 to 0.93 & 0.04 \\
& Female driver & 1.96 & 0.99 to 4.00 & 0.05 \\
Age & Female passenger & 0.66 & 0.29 to 1.47 & 0.31 \\
TWMV power capacity & 10 years more & 1.18 & 0.95 to 1.45 & 0.14 \\
Consider helmet useful & 1 category more & 1.52 & 1.30 to 1.75 & 0.0001 \\
\multirow{2}{*}{ Driving licence } & Yes & 2.13 & 1.35 to 3.33 & 0.001 \\
Issue year of the driving licence & No & 1.00 & & \\
& Yes & 1.59 & 0.73 to 3.45 & 0.25 \\
& No & 1.00 & & \\
& 1 year more & 1.00 & 0.97 to 1.03 & 0.94 \\
\hline
\end{tabular}

roads (having one lane for each direction), five systematically selected main road arteries (which run inside the city and suburban area and have two or more lanes for each direction), and five sites on the principal highways linking the capital of Athens with the rest of the country. According to the Hellenic Road Traffic Police Department this scheme allows a reasonable approximation to random sampling, given the different traffic density in the road system of the Greater Athens area. During the survey, 982 TWMVs were stopped and all 1331 involved TWMV riders were interviewed. After the TWMV was stopped, the interviewer ascertained helmet use by the TWMV riders and completed a structured questionnaire with a few open ended questions concerning basic sociodemographic data as well as vehicle related variables. The interview ended with recommendations for helmet use at all times. In no instance were the riders fined for non-use of helmet or any other road traffic violation during this survey.

For the analysis, simple cross tabulations were initially used; subsequently the data were modeled through multiple logistic regression to evaluate factors affecting helmet use, controlling for possible confounding by other variables. $^{25} 26$

\section{Results}

Table 1 presents the distribution of the 1331 TWMV riders by helmet use and, alternatively, by a series of the studied variables. These data incorporate confounding and should be interpreted with caution. Overall, only $20.2 \%$ of TWMV riders were using helmets of any type. The prevalence of use ranged from $9.7 \%$ on small suburban roads to $50.8 \%$ on highways. Older and female TWMV riders appear to be more frequent helmet users, as are riders of TWMVs with higher engine capacity. There is also some evidence that helmet use is more frequent during day rather than night hours and during weekdays rather than weekends. There were very few unlicensed drivers (4\%) but a substantial number of passengers were unlicensed $(82 \%)$ and they were less likely to use a helmet compared with those who were licensed. A considerable proportion of riders $(19 \%)$ claimed that use of a helmet increased rather than decreased the risk of an injury by reducing their field of vision, creating discomfort, etc.

Table 2 presents multiple logistic regression derived odds ratios for helmet use associated with a series of potential risk factors. This table allows a better assessment of mutually independent associations between several variables, on the one hand, and helmet use on the other. The odds for helmet use were 10 times higher in highways in comparison with small suburban roads. During the weekends and night hours the prevalence of helmet use was significantly lower. Passengers were less likely than drivers to wear helmets and, after controlling for riding position, the odds of a woman using a helmet were almost twice those of a man. Riders of larger engine capacity TWMVs were 
significantly more likely to wear a helmet. Helmet non-users were more likely to claim that they were not convinced about the safety benefits conferred by helmets. No statistically significant association was found for helmet use with age and time since obtaining a TWMV driving license, when the other indicated factors were controlled for in the regression model.

Among helmet non-users, the majority $(46 \%)$ indicated that "the helmet made them feel uncomfortable", particularly in warm weather. Altogether $18 \%$ claimed that there was little need for helmet use in low speed riding. Fewer than $5 \%$, but more than $1 \%$ of helmet non-users attributed non-use to such reasons as (in decreasing frequency): "the helmet was too expensive to buy", "it would be stolen during small errands or entertainment in the city", they "forgot it", it disturbed "the vision", "hearing", or "the shape of hairstyle", etc. Fewer than $1 \%$ of non-users claimed that they were unable to wear one because they had to make frequent stops on account of their job (letter and package couriers), or that they did not want to look like terrorists, or they invoked strange health reasons. A notably large number (26 riders) claimed that they did not like the helmet or that they actually felt uncomfortable when wearing it, but they nevertheless complied with the law that required carrying rather than wearing a helmet!

\section{Discussion}

This study has several advantages. The sample was reasonably large and designed to be representative. There were essentially no refusals and the information elicited during the interviews allowed for a better documentation of factors affecting the use or non-use of helmets in comparison with simple observational surveys. Moreover, the study was the first of its kind undertaken in Greece. It illustrates a major public health problem that underlies the high incidence of injuries among TWMV riders in this country. ${ }^{24}$ Although none of the results was unexpected, the extremely low prevalence of use, and the quantification of the patterns of non-use should allow rational planning of measures to increase use of these protective devices. It is possible that the sampling method used did not generate representative estimates in the strict statistical sense but all our results were presented conditioned on the possible selection factors (age, gender, type of road, etc) and moreover, the overall results were too striking to be explained by minor biases.

It has been established that helmets provide considerable protection in TWMV crashes. ${ }^{12-17}$ In a study in Greece, the risk of death associated with helmet use was reduced by $36 \%{ }^{24}$ The high relative risk for injuries during TWMV crashes, associated with helmet nonuse, generates a high attributable risk, because transportation by TWMVs is so common. Moreover, TWMV use is increasing in Greece, particularly in large cities, such as Athens, but also in the isolated parts of Greek islands and other urban settings. There are currently some 600000 motorbikes in Athens, mostly of small engine capacity and mostly used by younger people. It is sad that when the Scandinavian countries have succeeded in achieving almost universal use of helmets by TWMV riders, and are now trying to extend the use of helmets to bicyclists as well, the use of helmets among TWMV riders in Greece is limited to fewer than a quarter of TWMV riders, at least during the hot summer months of July and August.

Several years ago Geoffrey Rose pointed out a public health paradox. ${ }^{27}$ Those relatively few people at high risk for an untoward event-be it stroke among those with high blood pressure, heart attack among those with very high concentrations of blood cholesterol, or head injuries among high speed TWMV riders-are likely to benefit most from the application of respective preventive measures. Therefore, they are highly motivated to adopt the proposed preventive measures. Nevertheless, the attributable risk, which best reflects a public health problem, is mostly contributed to by the far larger number of those who are at moderately increased risk-in this instance, medium speed TWMV riders in city conditions. In our study, more than $50 \%$ of those riding in highways were using a helmet, whereas the prevalence of helmet use was less than 15\% among the far larger number of TWMV users riding in main city and suburban roads. A substantial fraction of injuries and deaths could be avoided if the latter group was targeted with the same intensity.

The results of this investigation also highlight other important problems. The likelihood of helmet use is lower during weekends, when many crashes occur, and during the night hours, when the severity of these injuries is generally higher. Male drivers and passengers are more frequently risk takers in comparison with their female counterparts, whereas those with a TWMV driving license and/or understanding of the function of a helmet are more likely to use one. ${ }^{28}{ }^{29}$ The results and the conclusions derived from studying these factors provide the necessary documentation for the priorities for campaigns or measures targeting extensive helmet use by TWMV riders. ${ }^{52}$ In addition, personal complaints, such as those concerning the field of vision, hearing ability, or hairstyle, should be taken into account. ${ }^{30-32}$

Reasons for non-use of helmets are revealing. Helmets have been primarily and extensively used in North American and Northern European countries, so that their design did not take into account the hot weather conditions prevailing in the Mediterranean countries. Moreover, most TWMV riders in Greece ride small engine capacity mopeds, which are relatively inexpensive. For the young and financially stressed TWMV rider, it may appear irrational to pay an extra $20 \%$ to purchase a standard helmet in addition to the light TWMV he has just managed to buy, or to even think about replacing the helmet according to the indicated date of expiration. ${ }^{33} 34$

Epidemiology and preventive medicine have been criticized for having gradually lost their 
social origin and public health perspective..$^{35} 36$ This may or may not be generally true but there are some situations in which it certainly is. Mortality and morbidity from TWMV injuries are major public health problems in many countries, including Greece and other Mediterranean countries. ${ }^{24}{ }^{37}$ Thus, it is sad to realize how little attention TWMV injuries have received in the mainstream epidemiologic research. Our results indicate that there is an urgent need for a multipronged campaign in Greece to increase the prevalence of helmet use by TWMV riders. The campaign should include not only police enforcement but also initiatives to make helmets more convenient to wear and less expensive.

1 European Transport Safety Council. A strategic road safety plan for the European Union. Brussels: European Transport plan for the European Uni

2 Reeder AI, Chalmers DJ, Langley JD. Rider training, reasons for riding, and the social context of riding among young on-road motorcyclists in New Zealand. Aust $N Z \mathcal{F}$ Public Health 1996;20:369-74

3 Coggan CA, Disley B, Patterson P, et al. Risk-taking behaviours in a sample of New Zealand adolescents. Aust $\mathrm{NZ}^{\prime}$ Public Health 1997;21:455-61.

4 Reeder AI, Chalmers DJ, Marshall SW, et al. Psychological and social predictors of motorcycle use by young adult males in New Zealand. Soc Sci Med 1997;45:1357-76.

5 Reeder AI, Chalmers DJ, Langley JD, et al. Motorcycling attitudes and behaviours. II. 14 and 15 year old adolescents. F Paediatr Child Health 1992;28:387-94.

6 Nurchi GC, Golino P, Floris F, et al. Effect of the law on compulsory helmets in the incidence of head injuries compulsory helmets in the incidence of head injuric

7 Sosin DM, Sacks JJ, Holmgreen P. Head injury-associated deaths from motorcycle crashes. Relationship to helmetdeaths from motorcycle crashes. Re.

8 Lund AK, Williams AF, Womack KN. Motorcycle helmet use in Texas. Public Health Rep 1991;106:576-8.

9 Kraus JF, Peek C, McArthur DL, et al. The effect of the 1992 California motorcycle helmet use law on motorcycle crash fatalities and injuries. $\mathcal{F} A M A$ 1994;272:1506-11.

10 Kraus JF, Peek C. The impact of two related prevention strategies on head injury reduction among nonfatally injured motorcycle riders, California, 1991-1993. F Neurotrauma 1995;12:873-81.

11 Peek-Asa C, Kraus JF. Estimates of injury impairment after acute traumatic injury in motorcycle crashes before and after passage of a mandatory helmet use law. Ann Emerg Med 1997;29:630-6.

12 Rutledge R, Stutts J. The association of helmet use with the outcome of motorcycle crash injury when controlling for outcome of motorcycle crash injury when controlling
crash/injury severity. Accid Anal Prev 1993;25:347-53.

13 Maimaris C, Summers CL, Browning C, et al. Injury patterns in cyclists attending an accident and emergency department: a comparison of heln

14 Ding SL, Pai L, Wang JD, et al. Head injuries in traffic accidents with emphasis on the comparisons between motorcycle-helmet users and non-users. $f$ Formos Med Assoc 1994;93(suppl 1):S42-8.

15 Panichaphongse V, Watanakajorn T, Kasantikul V. Effects of law promulgation for compulsory use of protective helmets on death following motorcycle accidents. 7 Med Assoc Thai 1995;78:521-5.

16 Sarkar S, Peek C, Kraus JF. Fatal injuries in motorcycle riders according to helmet use. F Trauma 1995;38:242-5.

17 Van Camp LA, Vanderschot PM, Sabbe MB, et al. The effect of helmets on the incidence and severity of head and cervical spine injuries in motorcycle and moped accident victims: a prospective analysis based on emergency department and trauma centre data. European fournal of Emergency Medicine 1998;5:207-11.

18 Muller A. Evaluation of the costs and benefits of motorcycle helmet laws. Am f Public Health 1980;70:586-92.

19 Hartunian NS, Smart CN, Willemain TR, et al. The economics of safety deregulation: lives and dollars lost due to repeal of motorcycle helmet laws. $\mathcal{F}$ Health Polit Policy Law 1983;8:76-98.

$20 \mathrm{McSwain}$ NE Jr, Belles A. Motorcycle helmets-medical costs and the law. F Trauma 1990;30:1189-97.

21 Braddock M, Schwartz R, Lapidus G, et al. A populationbased study of motorcycle injury and costs. Ann Emerg Med 1992;21:273-8.

22 Muelleman RL, Mlinek EJ, Collicott PE. Motorcycle crash injuries and costs: effect of a reenacted comprehensive helmet use law. Ann Emerg Med 1992;21:266-72.

23 Shankar BS, Ramzy AI, Soderstrom CA, et al. Helmet use, patterns of injury, medical outcome, and costs among motorcycle drivers in Maryland. Accid Anal Prev 1992;24: 385-96.

24 Petridou E, Skalkidou A, Ioannou N, et al. Fatalities from non-use of seat belts and helmets in Greece: a nationwide appraisal. Accid Anal Prev 1998;30:87-91.

25 MacMahon B, Trichopoulos D. Epidemiology: principles and methods. 2nd Ed. Boston: Little Brown, 1996.

26 Hosmer DW, Lemeshow S. Applied logistic regression. Wiley series in probability and mathematical statistics. Applied probability and statistics section. New York: John Wiley, 1989

27 Rose G. The strategy of preventive medicine. New York: Oxford University Press, 1994.

28 Kraus JF, Anderson C, Zador P, et al. Motorcycle licensure, ownership, and injury crash involvement. Am 7 Public Health 1991;81:172-6.

29 Reeder AI, Chalmers DJ, Langley JD. The risky and protective motorcycling opinions and behaviours of young on-road motorcyclists in New Zealand. Soc Sci Med 1996; 42:1297-311.

30 National Highway Traffic Safety Administration. Do motorcycle helmets affect riders' vision and hearing? Ann Emerg Med 1997;29:282-3.

31 McKnight AJ, McKnight AS. The effects of motorcycle helmets upon seeing and hearing. Accid Anal Prev 1995;27: 493-501.

32 Conrad P, Bradshaw YS, Lamsudin R, et al. Helmets, injuries and cultural definitions: motorcycle injury in urban Indonesia. Accid Anal Prev 1996;28:193-200.

33 Tsai YJ, Wang JD, Huang WF. Case-control study of the effectiveness of different types of helmets for the prevention of head injuries among motorcycle riders in Taipei, Taiwan. Am $\mathcal{F}$ Epidemiol 1995;142:974-81.

34 Peek-Asa C, McArthur DL, Kraus JF. The prevalence of non-standard helmet use and head injuries among motorcycle riders. Accid Anal Prev 1999;31:229-33.

35 Rothman KJ, Adami HO, Trichopoulos D. Should the mission of epidemiology include the eradication of poverty? Lancet 1998;352:810-3.

36 McMichael AJ. Prisoners of the proximate: loosening the constraints on epidemiology in an age of change. Am f Epidemiol 1999;149:887-97.

37 Anonymous. Helmet use among adolescent motorcycle and moped riders-Rome, Italy, 1996. MMWR Morb Mortal Wkly Rep 1996;45:311-4. 